\title{
Length-Weight Relationship of Crescent Perch Terapon Jarbua (Forsskal) from Parangipettai Coast, South East Coast of India
}

\author{
Manoharan J*, Gopalakrishnan A, Varadharajan D, Udayakumar C and Priyadharsini S
}

Faculty of Marine Sciences, Centre of Advanced Study in Marine Biology \& Department of Zoology, Annamalai University, Parangipettai, Tamil Nadu, India

\begin{abstract}
The present study investigates the length-weight relationship of T. jarbua from east coast of India. A total of 210 individuals was collected from Parangipettai landings centre. Lenght-weight relationships were collected for all specimens sampled. The results obtained were: $\log =0.4141+1.4229 \log L$ for males and $\log W=0.0977+1.6745$ $\log L$ for females. The growth exponential (b) values were different for both sexes, an isometric growth $(b=3)$ and $a$ negative allowmetric pattern $(b<3)$ were observed in males adfemales respectively.
\end{abstract}

Keywords: Length-Weight; Relationships; Male; Female; T. jarbua

\section{Introduction}

The fish culture is yet to be developed in India, with the large number of fishes present in both marine and freshwater systems. The length-weight relationships (LWR) are significantly important in fisheries science. In fact, these data become one of the standard methods employed in fishery biology. This information is required for the estimation of weight, where only length data are available and vice versa [1,2] suggests that the length - weight relationship is calculated primarily with two aims: 1) to determine the mathematical relation between the two variables, length and weight, in which if one variable is known, the another could be computed; 2), to measure the variations from the expected weight from the length of individual or group fishes as inaction of fatness $[1,3,4]$. These parameters are often used to calculate standard stock biomass, condition indices, ontogenetic changes and other aspects of fish population dynamics [3-5]. However, the growth parameters estimated of LWR can diverge substantially from true estimates of the population parameters due to inadequate sampling designs [6]. The application of LWR includes estimation of the mean weight of fish of a given body length and, conversion of the lengthgrowth model to corresponding weight growth model $[7,8]$ reported that the basic information on LWR is of a great importance, but often not available or insufficient. The study of LWR for fish resources of India are limited and the present study is focused on compensating this gap of information in the area. The length-weight relationship of T. jarbua has not been studied previously. Moreover, due to the high demand of T. jarbua in the country, , the use of LWR would be very useful for assessment of their maturity, growth and production Hence, the present study of the length-weight relationship of T. jarbua was performed with the objective of providing a set of estimated equations and determining whether anydifference exists in both sex [9].

\section{Materials and Methods}

The fishes for the present study was collected from Parangipettai landing centre (Lat.11 $1^{\circ} 29^{\prime} \mathrm{N}$; Long. $79^{\circ} 46^{\prime} \mathrm{E}$ ) during the month of January 2010- December 2010. To determine the length-weight relationships of T. jarbua, a total of 210 specimens were analysed (Figure 1). A total of 90 males ranging between $12.5-37.5 \mathrm{~cm}$ (TL) and 75.3-473.2 g of total weight (TW), and120 females, ranging between 12.1-36.9 cm TL and 79.5- 494.5g of total weight (TW) were sampled ( Figures 2 and 3$)$. The total length of the fish was measured $(\mathrm{cm})$ from the tip of the snout to the distal end of the caudal fin and the fish was weighed ( $\mathrm{g}$ ) after draining the water from the buccal cavity and blot- drying excess water in the body as it was reported in previous studies $[1,3,4,10]$.

The relationship between length and weight for fish in a given population can be analyzed by measuring the length and weight of the same fish repeatedly throughout its life span, or by measuring the weights and lengths of a sample of fish taken at a particular time $[6,10]$. The relationship between length $(\mathrm{L})$ and weight $(\mathrm{W})$ typically takes the form $[11,12]$ :

\section{$\mathrm{W}=\mathrm{aLb}$}

Or in the linear form:

$\log \mathrm{W}=\log \mathrm{a}+\mathrm{b} \log \mathrm{L}$

(i.e) $y=a+b x$

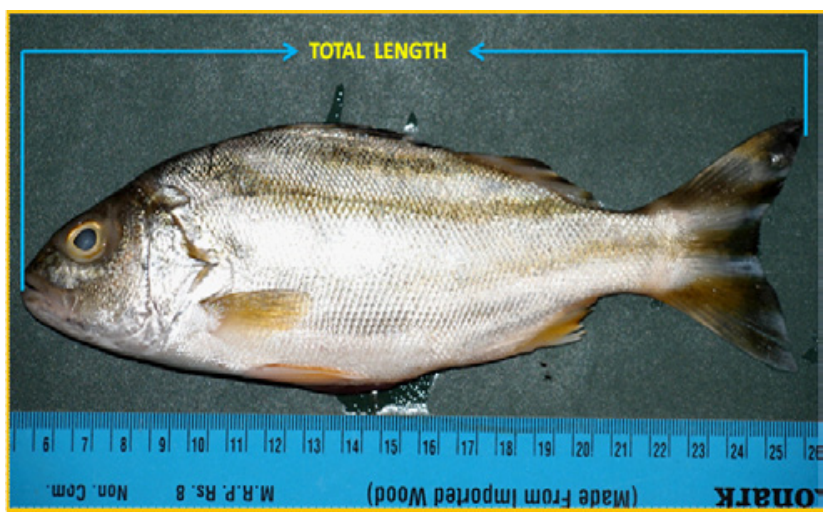

Figure 1: Total length of $T$. jarbua.

*Corresponding author: J. Manoharan, Faculty of Marine Sciences, Centre of Advanced Study in Marine Biology, Annamalai University, Parangipettai-608 502, Tamil Nadu, India; Tel: 04144-243223; Fax: 04144-243553; Fax: +171-442-4155; E-mail:manoaqua@gmail.com

Received February 07, 2013; Accepted March 29, 2013; Published April 09, 2013

Citation: Manoharan J, Gopalakrishnan A, Varadharajan D, Udayakumar C, Priyadharsini S (2013) Length-Weight Relationship of Crescent Perch Terapon Jarbua (Forsskal) from Parangipettai Coast, South East Coast of India. J Aquac Res Development 4: 181 doi:10.4172/2155-9546.1000181

Copyright: (c) 2013 Manoharan J, et al. This is an open-access article distributed under the terms of the Creative Commons Attribution License, which permits unrestricted use, distribution, and reproduction in any medium, provided the original author and source are credited. 
Citation: Manoharan J, Gopalakrishnan A, Varadharajan D, Udayakumar C, Priyadharsini S (2013) Length-Weight Relationship of Crescent Perch Terapon Jarbua (Forsskal) from Parangipettai Coast, South East Coast of India. J Aquac Res Development 4: 181 doi:10.4172/21559546.1000181

Page 2 of 3

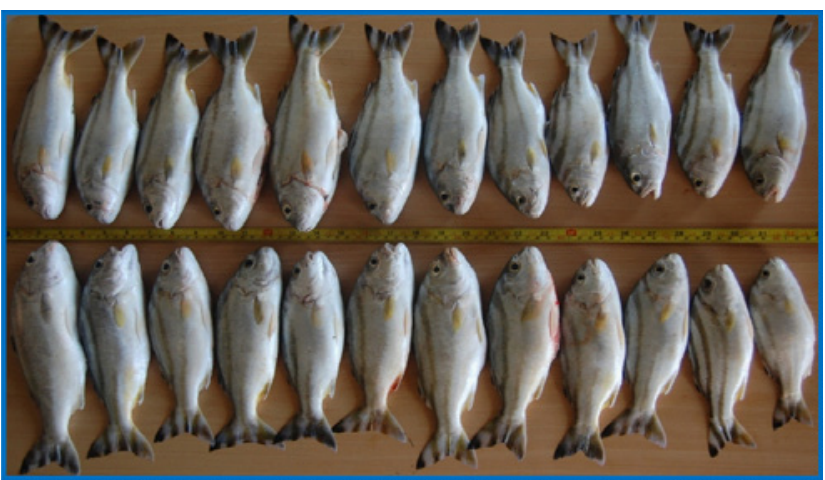

Figure 2: Different size of fishes used for length and weight measurement.

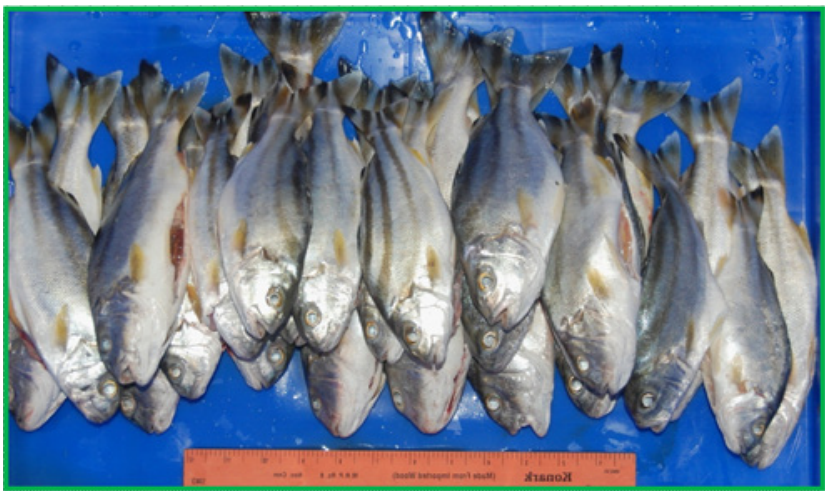

Figure 3: Different size group of fish subjected to measure length and weight.

\begin{tabular}{|l|c|c|c|c|}
\hline $\begin{array}{l}\text { Sex/linear } \\
\text { regression }\end{array}$ & Regression equation & a & B & $\mathbf{R}^{2}$ \\
\hline Males & Log $W=0.4141+1.4229 \log \mathrm{L}$ & 0.414 & 1.4229 & 0.9569 \\
\hline Females & Log $\mathrm{W}=0.0977+1.6745 \log \mathrm{L}$ & 0.0977 & 1.6745 & 0.9728 \\
\hline
\end{tabular}

Table 1: Regression parameters for length-weight relationship of male and female $T$. jarbua.

\section{Whereas,}

$\mathrm{a}=$ intercept; $\mathrm{y}=\log \mathrm{W}$;

$\mathrm{x}=\log \mathrm{L} \mathrm{b}=$ slope.

According to [10], ' $\mathrm{W}$ ' represents the weight of the fish in grams and ' $a$ ' and ' $b$ ' the constants, which were estimated by the method of least squares.

\section{Results}

The parameters of the LWR of T. jarbua, together with the regression coefficient ( $r$ ) the range and the number of specimens measured (n) are presented in Table 1 . The values for the exponent (b) remain mostly within the expected range of 0.5-4.0, suggesting that these parameters can be used safely within the length range indicated. The regression line derived from the data for the T. jarbua showed a linear relationship between the two variables: length and weight. In males and females of $T$. jarbua, minimum length and weight groups were in the range between 12.5 to $37.5 \mathrm{~cm}$ and total weight (TW) 75.3 to $473.2 \mathrm{~g}$, while in females, the size range between 12.1 to $36.9 \mathrm{~cm}$ TL and total weight (TW)
79.5 to $494.5 \mathrm{~g}$ were found respectively during the study period. The mathematical relationship between total length and weight of males, females and intermediate stages of T. jarbua obtained by logarithmic regression equations are as follow: $\mathrm{W}=\log \mathrm{a}+\mathrm{b} \log \mathrm{L}$.

The R2 values were different for both sex. In males this value was 0.9569 and in females 0.9728 were recorded respectively during the study period (Table 1 ). The regression parameters are ' $n$ '=number, 'a,=weight of specimen and ' $\mathrm{b}$ '=total length and $\mathrm{R}^{2}=$ regression, among the linear equation. The 'a' value in males was estimated at 0.414 and in females at 0.0977 , while the 'b' value was 1.4229 in males and 1.6745 females during the study period (Figures 4 and 5).

\section{Discussion}

The length-weight relationships have played an important factor for fisheries [12]. Cube law is not confirmed for all fishes because the growth could change their shapes $[13,14]$ also described that a value less than 3 would indicate that fishes become lighter (negative allometric) and greater than 3 as heavier (positive allometric) for a particular length as well as increase in size. In the present study, it was observed that the LWR of T. jarbua increases at the rate of cube. In male and female specimens, the ' $b$ ' values were 1.4229 and 1.6745 respectively. According to [14], the 'b' values were almost equal to the expected value of ' 3 ' for ideal fish in both sex It is important to notice that these values can differ based on factors such as season, food and feeding of the species $[3,4]$, in males the results indicated a lower weight than those obtained in females, showing differences in maturation and spawning. This results suggested an isometric growth $(b=3)$ in males and a

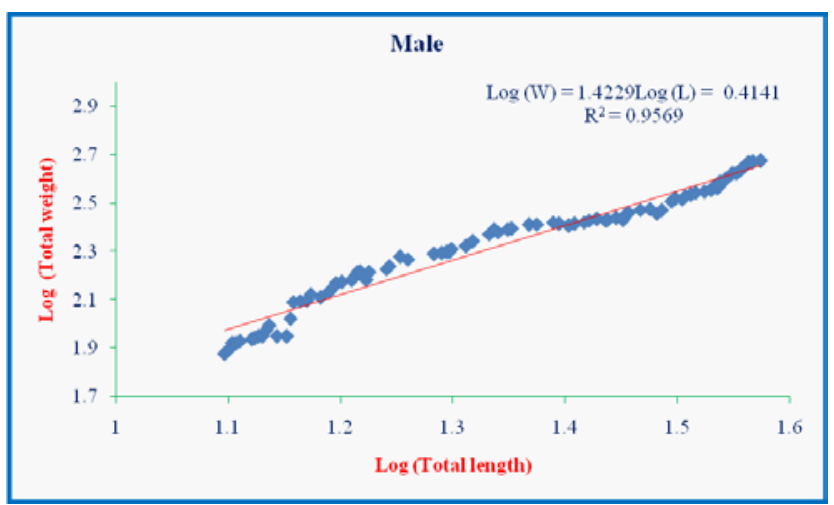

Figure 4: Length-Weight relationship of male $T$. jarbua.

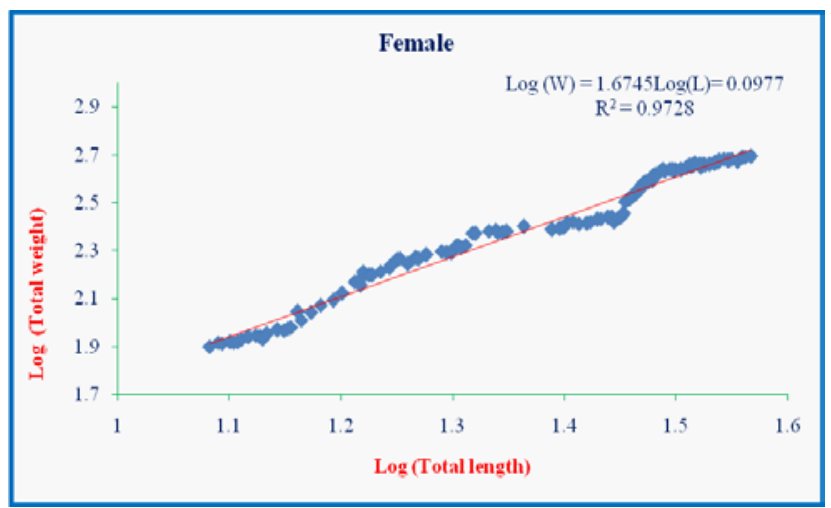

Figure 5: Length-Weight relationship of female T. jarbua. 
Citation: Manoharan J, Gopalakrishnan A, Varadharajan D, Udayakumar C, Priyadharsini S (2013) Length-Weight Relationship of Crescent Perch Terapon Jarbua (Forsskal) from Parangipettai Coast, South East Coast of India. J Aquac Res Development 4: 181 doi:10.4172/21559546.1000181

negatively allometric pattern $(b<3)$ in females, indicating that the rate of increasing in body length is not proportional to the rate of increase in the body weight. In addition, this was different by months and seasons and the result for pooled values in both sexes presented $90 \%$ of negative allometric growth $(b<3)$. This change may be due to a number of factors including season, habitat, gonad maturity, sex, diet, stomach fullness, health, preservation techniques and locality $[13,15,16]$. Such differences in value ' $b$ ' can be assigned to a combination of factors such as differences in the number of specimens examined, area/season effects and the differences of length range analysed of the specimens caught. Furthermore, the duration of samples collection can be added. According to $[17,18]$ the slope value ' $b$ ' indicates the rate of weight gain relative to growth in length and varies among different populations of the same species or within the same species.

In the present study, the LWR for T. jarbua indicated that length increased with weight. This is in agreement with previous studies on different fish species from various water systems $[12,13,15]$. The increasing in weight of any individual was not to a single factor but also a mix of them [19]. The factors could be either intrinsic or extrinsic, or both, and favoured by the changes of the growth parameters length and weight of the fish [20]. In general, males were heavier than females in some times it may full of stomach and females are heavier than male for one time. This variation might be due to the feeding and availability of food. In addition, females have to divert a considerable part of the energy for oogenesis and to carry eggs and, also spend more energy during the breading after spend the eggs female feeding more than male.According to [21] 'b' values were below 3.5 suggesting that results of this study are valid.

The present study provides baseline information on the lengthweight relationship for T. jarbua in the area. An isometric growth pattern is pronounced in males and females of this species during the study period. Feeding activity and reproduction cycle are the main factors influencing the condition of the species. It may be concluded that the growth of females is quiet acceptable and the overall growth performance of females show higher growth in relation to weight increment than males. T. jarbua contain mixed length-weight relationship, lengths were higher in males. Conversely, the weights were heavier in females, which could be relating to the continuous breeding of this species. Based on the these factors, the T. jarbua species is recommended to be used for aquaculture practices. In conclusion, this study provides new knowledge about the length-weight relationship of T. jarbua suitable in fisheries management.

\section{References}

1. Kartha KN, Rao KS (1990) Length-weight and Length-maximum Girth Relationship of Catla catla (Ham.) in Commercial Landings of Gandhi Sagar Reservoir. Fish Technol 27: 155-156.

2. LeCren CD (1951) The length-weight relationship and seasonal cycle in gonad weight and condition in perch, Perca fluviatilis. J Animal Ecol 20: 201-209.

3. Kurup BM, Samuel CT (1987) Length-weight Relationship and Relative Condition Factor in Daysciaena albida (Cuv.) and Gerres filamentosus (Cuv.) Fish Technol 24: 88-92.

4. Sunil MS (2000) Length-weight Relationship in Rasbora danicnius (Ham.) from Achenkoli River, Pathanamthitta. Kerala, India. Indian J Fish 47: 271-274.
5. Mohan MV, Sankaran TM (1988) Length-weight Relationship of Indian major Carps with Improvement in Expressing, Exponential Formula. J Aquacult Trop 3: 43-46.

6. Gowda G, Shanbougu SL, Udupa KS (1987) Length-weight relationship and relative condition of Grey mullet, Valamugil sehci (Forskal), from Manglore waters. Indian J Fish 34: 340-342.

7. Antony RPT (1967) Length weight relationship in the oil sardine Sardinella longicep. Val Indian J Fish 14: 159-190.

8. Campos OJF, Escala MC (2005) Length-weight relationships of some fish species of the Iberian Peninsula. J Appl Ichthyol 21: 73-74.

9. Vazzoler AE (1996) Biologia dareproducao depeixes Teleosteos: teoria e pratic EDUEM, SBI, Maringa Pp 169.

10. Ramaseshaiah M, Murthy VSR (1997) Length weight and total lengthcarapace length relationships of Metapenaeus barbatrs (De Haan) from the Vishakapatnam coast. Indian J Fish 44: 91-95.

11. Sunil Kumar G, Mercy TVA, John KC (1999) Length-weight relationship of the catfish Horabagrus brachysoma (Gunther). Indian J Fish 46: 191-193.

12. Atkinson DB (1989) Weight-length relationship of roundnose grenadier (Coryphaenoides rupestris) (Gunnerus, 1765) in different areas of the North Atlantic. Fish Res Amsterdam 7: 65-72.

13. Wooton RJ (1990) Ecology of Teleosts fish. Chapman and Hall, London pp 404

14. Froes $R$ (2006) Cube law, condition factor and weight-length relationships: history, meta-analysis and recommendations. J Appl Ichthyol 22: 241-253.

15. Jhingran AG (1968) The length-weight relationship and K factor of Gudusia chapra (Ham) from the Ganga river system. Proc Nat Acad Sci India 88B: 249263.

16. Frosta IO, Costa PAS, Braga AC (2004) Length-weight relationships of marine fishes from the Central Brazilian Coast Naga. World fish centre Quarterly 27: 20-26.

17. Townsend CR, Silva LVF, Baldisserotto B (2003) Growth and survival of Rhamdia quelen (Siluriformes, Pimelodidae) larvae exposed to different levels of water hardness. Aquacult 215: 103-108.

18. Altinok I, Grizzle JM (2001) Effects of brackish water on growth, feed conversion and energy absorption efficiency by juveniles euryhaline and freshwater stenohaline fishes. J Fish Biol 59: 1142-1152.

19. Pauly D, Gayanilo Jr FC (1997) ABee: An alternative approach to estimating the parameters of a length-weight relationship from length-frequency samples and their bulk weights. ICLARM, Manila, Philippines.

20. Torres MA, Ramos F, Sobrino I (2012) Length-weight relationships of 76 fish species from the Gulf of Cadiz (SW Spain). Fisheries Research 127-128: 171175

21. Froese R, Pauly D (2012) FishBase. World Wide Web electronic publication version. 